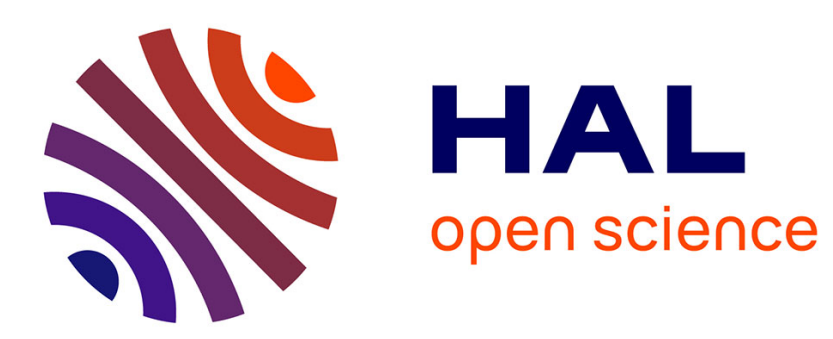

\title{
The family of LiCo6P4 type compounds - trends in electronic structure and chemical bonding
}

\author{
Samir F. Matar, Rainer Pöttgen
}

\section{To cite this version:}

Samir F. Matar, Rainer Pöttgen. The family of LiCo6P4 type compounds - trends in electronic structure and chemical bonding. Journal of Inorganic and General Chemistry / Zeitschrift für anorganische und allgemeine Chemie, 2014, 640 (8-9), pp.1641-1647. 10.1002/zaac.201400123 . hal-01052568

\section{HAL Id: hal-01052568 https://hal.science/hal-01052568}

Submitted on 7 Jul 2015

HAL is a multi-disciplinary open access archive for the deposit and dissemination of scientific research documents, whether they are published or not. The documents may come from teaching and research institutions in France or abroad, or from public or private research centers.
L'archive ouverte pluridisciplinaire HAL, est destinée au dépôt et à la diffusion de documents scientifiques de niveau recherche, publiés ou non, émanant des établissements d'enseignement et de recherche français ou étrangers, des laboratoires publics ou privés. 


\section{The family of $\mathrm{LiCo}_{6} \mathrm{P}_{4}$ type compounds - Trends in electronic structure and chemical bonding}

Samir F. Matar ${ }^{[a],}$, Rainer Pöttgen ${ }^{[\mathrm{b}], *}$

Running title: $\mathrm{LiCo}_{6} \mathrm{P}_{4}$-type compounds

Keywords: $\mathrm{LiCo}_{6} \mathrm{P}_{4}$-type structure, Electronic structure, Trends in chemical bonding

Abstract. Selected ternary compounds of the family of $\mathrm{AT}_{6} \mathrm{X}_{4}$ (LiCo6 $\mathrm{P}_{4}$-type) intermetallics have been studied by ab initio methods with respect to their electronic structures and chemical bonding. The bonding characteristics highlight the role of the three-dimensional $\left[\mathrm{T}_{6} \mathrm{X}_{4}\right]$ polyanionic networks which, within the hexagonal channels, accommodate loosely bonded A cations. In alkali metal based compounds, when $\mathrm{T}$ is replaced by indium (e. g. in $\mathrm{KIn}_{6} \mathrm{Au}_{4}$ ) the reverse occupancy leads to positively charged In $(\sim+0.5)$ and negatively charged $\mathrm{Au}(\sim-0.9)$. Peculiar magnetic behavior is traced out whereby a magnetic order is identified only when $\mathrm{T}$ is a $3 \mathrm{~d}$ element which polarizes and induces a negative small moment on $\mathrm{A}(\mathrm{U})$ as in $\mathrm{UCr}_{6} \mathrm{P}_{4}$ oppositely to $\mathrm{CeRh}_{6} \mathrm{X}_{4}$ for $\mathrm{X}=$ $\mathrm{Si}, \mathrm{Ge}$.

* Prof. Dr. Rainer Pöttgen

Fax: +49-251-83-36002

E-mail: pottgen@uni-muenster.de

Dr. Samir F. Matar

Fax: +33-5-4000-2761

E-mail: matar@icmcb-bordeaux.cnrs.fr

[a] CNRS, Université de Bordeaux, ICMCB

87 Avenue Dr. A. Schweitzer

33608 Pessac-Cedex, France

[b] Institut für Anorganische und Analytische Chemie

Universität Münster

Corrensstrasse 30

48149 Münster, Germany 


\section{Introduction}

The complex metal-rich phosphide $\mathrm{LiCo}_{6} \mathrm{P}_{4}[1]$ is the prototype for a small series of compounds. LiCo6 $\mathrm{P}_{4}$ crystallizes with space group $P \overline{6} m 2$, Pearson symbol hP11 with one formula unit per cell. The structure comprises seven crystallographically independent sites. The representatives [2-7] with the different coloring on these sites are listed in Table 1. The phosphides and arsenides exist for cobalt and rhodium and the cation position of lithium can be substituted also by an alkaline earth metal. A peculiar example is the low-temperature phase of $\mathrm{UCr}_{6} \mathrm{P}_{4}$ with a distinctly lower valence electron count. Recently the first tetrelides with $\mathrm{LiCo}_{6} \mathrm{P}_{4}$ type structure were reported; the silicide $\mathrm{CeRh}_{6} \mathrm{Si}_{4}[5]$ and the series of germanides $R E \mathrm{Rh}_{6} \mathrm{Ge}_{4}(R E=\mathrm{Y}, \mathrm{La}-\mathrm{Nd}, \mathrm{Sm}-\mathrm{Lu})$ $[6,8]$. Thus, compounds with the $\mathrm{LiCo}_{6} \mathrm{P}_{4}$ type allow for certain flexibility in the valence electron concentration.

This peculiar structure type is built up from a rigid three-dimensional polyanionic network which leaves channels for the cations. The $\mathrm{CeRh}_{6} \mathrm{Ge}_{4}$ structure is exemplarily presented in Figure 1. The bonding variations in this structure type mainly result from the coloring within the polyanion. A very interesting bonding situation concerns the alkali metal compounds $\mathrm{KIn}_{6} \mathrm{Au}_{4}$ and $\mathrm{RbIn}_{6} \mathrm{Au}_{4}$ [7], where the transition metal and $p$ element atoms exchange their sites, a consequence of the high electronegativity of the gold atoms. Formally one can call $\mathrm{KIn}_{6} \mathrm{Au}_{4}$ and $\mathrm{RbIn} 6 \mathrm{Au}_{4}$ anti-types of $\mathrm{LiCo}_{6} \mathrm{P}_{4}$, similar to the well-known relationship perovskite-anti-perovskite.

So far only few of the $\mathrm{LiCo}_{6} \mathrm{P}_{4}$ type compounds have been studied with respect to their chemical and physical properties. $\mathrm{KIn}_{6} \mathrm{Au}_{4}$ is a Pauli paramagnet [9] and the germanides $R E \mathrm{Rh}_{6} \mathrm{Ge}_{4}(R E=\mathrm{Ce}, \mathrm{Gd}-\mathrm{Yb})[6,8]$ show Curie-Weiss behavior with experimental magnetic moments close to the free-ion values of $R E^{3+}$. The highest magnetic ordering temperature of $\mathrm{T}_{\mathrm{N}}=13.6 \mathrm{~K}$ occurs for $\mathrm{TbRh}_{6} \mathrm{Ge}_{4}$.

First studies on electronic structure and chemical bonding have been performed for $\mathrm{KIn}_{6} \mathrm{Au}_{4}$ [7], and $\mathrm{LiCo}_{6} \mathrm{P}_{4}$ [9]. Both structures show optimized covalent bonding in their $\left[\mathrm{In}_{6} \mathrm{Au}_{4}\right]^{\delta_{-}^{-}}$and $\left[\mathrm{Co}_{6} \mathrm{P}_{4}\right]^{\delta-}$ polyanionic networks and weaker cation-anion bonding. Total energy calculations of $\mathrm{LiCo}_{6} \mathrm{P}_{4}$ and the structurally closely related phosphide $\mathrm{Li}_{2} \mathrm{Co}_{12} \mathrm{P}_{7}$ indicated stability of the $\left[\mathrm{Co}_{6} \mathrm{P}_{4}\right]$ and $\left[\mathrm{Co}_{12} \mathrm{P}_{7}\right]$ substructures upon de-lithiation. These 
studies were performed in the context of ternary tetrelides and pnictides with potential lithium mobility [10-13].

In extension of our synthetic work on $\mathrm{LiCo}_{6} \mathrm{P}_{4}$ type compounds we have now studied the electronic structures and chemical bonding of the whole family in the context of DFT based calculations [14, 15], focusing on the electronic structure (density of states, magnetic ground states) as well as trends in the cohesive energies, the atomic charges and the overlap populations providing hints on the properties of chemical bonding.

\section{Computational methodologies}

Two computational methods within the DFT $[14,15]$ were used in a complementary manner. The Vienna ab initio simulation package (VASP) code [16, 17] allows geometry optimization and cohesive energy calculations. For this we use the projector augmented wave (PAW) method [17], with the generalized gradient approximation (GGA) scheme following Perdew, Burke and Ernzerhof (PBE) [18]. Semi-core electrons of $\mathrm{Li}, \mathrm{K}, \mathrm{Rb}, \mathrm{Mg}, \mathrm{Ca}, \mathrm{Sr}$ states were considered upon building the respective PAW potentials. Preliminary calculations with local density approximation LDA [19] led to largely underestimated volumes versus the experiment. The conjugate-gradient algorithm [20] is used in this computational scheme to relax the atoms. The tetrahedron method with Blöchl corrections [21] as well as a Methfessel-Paxton [22] scheme was applied for both geometry relaxation and total energy calculations. Brillouin-zone (BZ) integrals were approximated using the special k-point sampling. The optimization of the structural parameters was performed until the forces on the atoms were less than 0.02 $\mathrm{eV} / \AA$ and all stress components less than $0.003 \mathrm{eV} / \AA^{3}$. The calculations are converged at an energy cut-off of $500 \mathrm{eV}$ for the plane-wave basis set with respect to the k-point integration up to $8 \times 8 \times 13\left(\mathrm{k}_{\mathrm{x}}, \mathrm{k}_{\mathrm{y}}, \mathrm{k}_{\mathrm{z}}\right)$ for best convergence and relaxation to zero strains. The calculations are scalar relativistic and assume spin degenerate total spins.

Then all-electron calculations with the GGA were carried out for a full description of the electronic structure and the properties of chemical bonding, using the augmented spherical wave (ASW) method devised by Williams, Kübler and Gelatt in 1979 [23] as a linearized method close to the LMTO (Linearized Muffin Tin Orbitals) method. It has benefited from continuous developments leading to full potential FP-ASW with 
implementation of chemical bonding according to different schemes (cf. the text book by V. Eyert [24] and therein references). The ASW method uses a minimal basis set for the valence states with the outermost shells representing one of each kind: the valence states and the matrix elements are constructed using partial waves up to $l_{\max }+1=4$ for Ce and $\mathrm{U}, l_{\max }+1=3$ for $T$, and $l_{\max }+1=2$ for $X$. Self-consistency is achieved when charge transfers and energy changes between two successive cycles were below $10^{-8}$ and $10^{-6} \mathrm{eV}$, respectively. $\mathrm{BZ}$ integrations were performed using the linear tetrahedron method within the irreducible wedge. Besides the site projected density of states, we discuss qualitatively the pair interactions based on the overlap population analysis with the crystal orbital overlap population (COOP) [25]. In the plots, positive, negative, and zero COOP indicate bonding, anti-bonding, and non-bonding interactions, respectively.

\section{Crystal chemical considerations}

Before starting the theoretical description we draw back to the crystal chemical details of the $\mathrm{LiCo}_{6} \mathrm{P}_{4}$ type phases. This peculiar structure type is realized for several pnictides, but recently also the first tetrelides have been reported. The different coloring of the atoms on the seven crystallographically independent sites is summarized in Table 1 .

Exemplarily we discuss the $\mathrm{CeRh}_{6} \mathrm{Ge}_{4}$ structure [6]. The rhodium and germanium atoms build up a rigid three-dimensional polyanionic $\left[\mathrm{Rh}_{6} \mathrm{Ge}_{4}\right]^{\delta-}$ network which is charge-balanced by the cerium atoms. The latter fill larger cavities within hexagonal channels left by the $\left[\mathrm{Rh}_{6} \mathrm{Ge}_{4}\right]^{\delta-}$ network (Figure 1$)$. The polyanion exhibits $\mathrm{Rh}-\mathrm{Ge}(247-$ $255 \mathrm{pm})$ and $\mathrm{Rh}-\mathrm{Rh}(285-291 \mathrm{pm})$ bonding. The $\mathrm{Rh}-\mathrm{Ge}$ distances are close to the sum of the covalent radii of $247 \mathrm{pm}$ [26] and the Rh-Rh distances are all slightly longer than in $f c c$ rhodium (269 pm) [27]. Similar crystal chemistry can be discussed also for the pnictides. Regarding the $\mathrm{Rh}-\mathrm{Rh}$ connections it might be relevant to discuss their nature in actual compound. This is illustrated by the plot of the COOP for the rhodium bonding within one substructure and between two substructures Rh1 and Rh2. Fig. 3 shows the plots obtained from self consistent total spins in $\mathrm{CeRh}_{6} \mathrm{Ge}_{4}$. The prevailing bonding is found between the Rh1 and Rh2 substructure whereas much weaker and similar COOP are exhibited for Rh1-Rh1 and Rh2-Rh2. Nevertheless the bonding (positive magnitudes along $y$ axis) COOP are compensated by antibonding (negative) within the VB so that 
the Rh-Rh bonding does not contribute to the stability of the compound. Those are rather the hetero-connections, such as $\mathrm{Co}-\mathrm{P}$ in $\mathrm{MgCo}_{6} \mathrm{P}_{4}$ (cf. Fig. 4) which are responsible of the cohesion of the ternary compounds.

An alternative description of the $\mathrm{CeRh}_{6} \mathrm{Ge}_{4}$ structure is possible via the coordination polyhedra (Fig. 2). The cerium atoms have coordination number (CN) 18 by six germanium and twelve rhodium atoms. These $\mathrm{CN} 18$ polyhedra fill the corners of the unit cell and they are stacked along the $c$ axis via common hexagonal faces. The second relevant polyhedron concerns the Ge1 atoms which have CN9 by rhodium atoms. These Ge1@Rh9 polyhedra fill the space between the corner-sharing (via rhodium atoms) Ce@ $\mathrm{Ge}_{6} \mathrm{Rh}_{12}$ polyhedra.

Besides the classical site occupancy variants, also the alkali metal compounds $\mathrm{KIn}_{6} \mathrm{Au}_{4}$ and $\mathrm{RbIn}_{6} \mathrm{Au}_{4}$ [7] with an inverse site occupancy have been reported. Comparing the $\left[\mathrm{In}_{6} \mathrm{Au}_{4}\right]^{\delta-}$ and $\left[\mathrm{Co}_{6} \mathrm{P}_{4}\right]^{\delta-}$ networks this switch in site occupancy is readily understandable on the basis of electronegativity arguments, $i$. $e$. the highly electronegative gold atoms substitute phosphorus, similar to the pairs of compounds $\mathrm{Hf}_{2} \mathrm{Co}_{4} \mathrm{P}_{3}$ vs. $\mathrm{Sr}_{2} \mathrm{In}_{4} \mathrm{Au}_{3}[28]$ and $\mathrm{YCo}_{5} \mathrm{P}_{3}$ vs. $\mathrm{Ca}_{2} \mathrm{In}_{4} \mathrm{Au}_{3}[29]$.

The second exception concerns the phosphides $\mathrm{ScRh}_{6} \mathrm{P}_{4}, \mathrm{YbRh}_{6} \mathrm{P}_{4}$, and $\mathrm{LuRh}_{6} \mathrm{P}_{4}$ [30]. They crystallize with a superstructure of the $\mathrm{LiCo}_{6} \mathrm{P}_{4}$ type, resulting from two translationengleiche symmetry reductions. Small atomic displacements allow for a weak puckering.

Finally we draw our attention to the valence electron count (VEC). Similar to many other families of intermetallics, also the $\mathrm{LiCo}_{6} \mathrm{P}_{4}$ type phases show a certain stability range. The smallest VEC of 73 occurs for the tetrelides like $\mathrm{CeRh}_{6} \mathrm{Ge}_{4}$ and the highest one of 79 for the aurides $\mathrm{KIn}_{6} \mathrm{Au}_{4}$ and $\mathrm{RbIn}_{6} \mathrm{Au}_{4}$. Keeping this range and the small number of representatives in mind, several other representatives are likely to exist. Nevertheless, their composition will only be discovered by serendipity.

\section{Results and discussion}

\subsection{Non-magnetic representatives}

\section{$\mathrm{MgCo}_{6} \mathrm{P}_{4}$}


Recent DFT investigations of $\mathrm{LiCo}_{6} \mathrm{P}_{4}$ together with $\mathrm{Li}_{2} \mathrm{Co}_{12} \mathrm{P}_{7}$ [9] have shown the particularity in both phosphides to exhibit strong Co-P bonding within the polyanionic networks $\left[\mathrm{Co}_{6} \mathrm{P}_{4}\right]^{\delta-}$ and $\left[\mathrm{Co}_{12} \mathrm{P}_{7}\right]^{\delta-}$, respectively. Less bonding between $\mathrm{Li}$ and the polyanions could let suggest a possible Li de-intercalation with favorable energetics.

From Table 2 the geometry optimized crystal structure results are found in relatively good agreement with the experiment for the internal coordinates (Co1, Co2, and P1) although slightly smaller hexagonal lattice parameters $a$ and $c$ are obtained. These trends are also observed for the other compounds studied in this paper.

Then the results can be used to examine energy trends and charge transfers. The cohesive energies can be obtained from the difference between the total electronic energy obtained at self consistent convergence on one hand and those of the atomic constituents $\mathrm{Mg}, \mathrm{Co}$ and $\mathrm{P}$ on the other hand in their ground state structures, i. e. hexagonal for $\mathrm{Mg}$ and $\mathrm{Co}$ and simple cubic for white phosphorous:

$\mathrm{E}\left(\mathrm{MgCo}_{6} \mathrm{P}_{4}\right)=-72.745 \mathrm{eV} ; \mathrm{E}(\mathrm{Mg})=-1.392 \mathrm{eV} /$ atom; $\mathrm{E}($ Co-hexagonal $)=-6.88$ $\mathrm{eV} /$ atom and $\mathrm{E}(\mathrm{P})=-5.24 \mathrm{eV} / \mathrm{atom}$. Taking the respective multiplicities into account, the resulting cohesive energy averaged per atom is $\mathrm{E}_{\text {coh. }}\left(\mathrm{MgCo}_{6} \mathrm{P}_{4}\right)=-0.828 \mathrm{eV}$ which is found slightly smaller in magnitude than the one obtained for the lithium compound, i. e. $\mathrm{E}_{\text {coh. }}\left(\mathrm{LiCo}_{6} \mathrm{P}_{4}\right)=-0.833 \mathrm{eV}$ [9]. This is concomitant with the larger electronegativity of $\mathrm{Mg}\left(\chi_{\mathrm{Mg}}=1.31\right.$ versus $\left.\chi_{\mathrm{Li}}=0.98\right)$ whereby $\mathrm{LiCo}_{6} \mathrm{P}_{4}$ is more ionic than $\mathrm{MgCo}_{6} \mathrm{P}_{4}$. A more quantitative approach of these features is obtained through the analysis of the electron transfers obtained from charge density analysis using the AIM (atoms in molecules theory) approach [31]. Typically in chemical compound, the charge density reaches a minimum between atoms and this is a natural region to separate them from each other. Such an analysis does not constitute a tool for evaluating absolute ionizations but allows establishing trends between similar compounds. For the $\mathrm{Mg}$ and Li based phosphides the average charge values $(\mathrm{Q})$ are:
LiCo6 $4: \quad \mathrm{Q}(\mathrm{Li})=+0.86 \quad \mathrm{Q}(\mathrm{Co})=+0.30 \quad \mathrm{Q}(\mathrm{P})=-0.66$

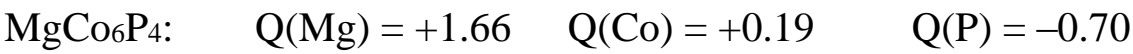

The almost twice larger positive charge carried by $\mathrm{Mg}$ arises from its divalent character, i.e. versus monovalent $\mathrm{Li}$. The consequence is a larger positive ionization of 
Co in the latter compound so that the negative charge carried by $\mathrm{P}$ is almost the same, i.e. close to $\sim-0.7$.

In so far as the calculated structure parameters are found close to the experimental values [2], the electronic structure and the properties of chemical bonding are calculated using the latter. They were started assuming spin degenerate non spin polarized (NSP) magnetic configuration. Spin polarized (SP) calculations were carried out for the Ce and $\mathrm{U}$ based magnetic compounds which present an instability in such NSP configuration. This is detailed in following sections.

With the all electrons ASW method, at self consistent convergence of the energies and charges, small charge transfers similar to the above trends were obtained. Fig. 4 shows the NSP site projected DOS-PDOS (top) and the chemical bonding (COOP) bottom- for $\mathrm{MgCo}_{6} \mathrm{P}_{4}$. Energy reference along the $x$ axis is with respect to the Fermi level EF. Due to the large filling of Co already at the atomic state $\left(4 s^{2}, 3 d^{7}\right)$ the largest part of Co-PDOS are found within the valence band (VB) and crossed by $\mathrm{E}_{\mathrm{F}}$ at the upper part. A metallic character can be traced out. The two Co sites (Co1, Co2) have similar PDOS as well as P which follow the shape of the Co PDOS especially in the $\{-$ $7,-3 \mathrm{eV}$ \} energy window i.e. in the region of the lower energy Co $d$ and $\mathrm{P} p$ states which mix leading to the chemical bonding ensuring for the stability of the ternary compound through the $\left[\mathrm{Co}_{6} \mathrm{P}_{4}\right]^{\delta-}$ entities, whereas the Mg PDOS are vanishingly small due to their itinerant $s$ character. The chemical bonding is discussed based on the overlap population analysis using the COOP scheme [25]. From the lower panel in Fig. 3 the major interactions within the $\mathrm{VB}$ are between $\mathrm{Co}$ and $\mathrm{P}$ through the $\left[\mathrm{Co}_{6} \mathrm{P}_{4}\right]^{\delta^{-}}$ polyanions; they are of bonding nature (positive COOP). The other contributions, $\mathrm{Mg}_{-}$ $\mathrm{Co}$ and $\mathrm{Mg}-\mathrm{P}$ are vanishingly small. This confirms the picture of a system presenting $\mathrm{Co} / \mathrm{P}$ substructures as building a skeleton in which $\mathrm{Li}$ and $\mathrm{Mg}$ are loosely bonded within the $\left[\mathrm{Co}_{6} \mathrm{P}_{4}\right]$ motifs. This feature which is inherent to the $\mathrm{LiCo}_{6} \mathrm{P}_{4}$ type should be found in all other members considered here with some differences pertaining to reverse site occupancies as in $\mathrm{AAu}_{4} \operatorname{In}_{6}(\mathrm{~A}=\mathrm{K}, \mathrm{Rb})$ or magnetic polarization with $\mathrm{A}=\mathrm{Ce}, \mathrm{U}$.

\section{Reverse site occupancies in $\mathrm{KIn}_{6} \mathrm{Au}_{4}$ and $\mathrm{RbIn}_{6} \mathrm{~A} \mathrm{u}_{4}$}

The alkali metal compounds $\mathrm{KIn}_{6} \mathrm{Au}_{4}$ and $\mathrm{RbIn}_{6} \mathrm{Au}_{4}$ [7] show an inverse site occupancy with respect to the classical site occupancy variants as the $\mathrm{Li}$ and $\mathrm{Mg}$ 
compounds. The electronic structure and bonding properties were studied with the LMTO code by Li and Corbett in 2007 [7] without pointing out to the charge changes that we address here based on Bader analysis of the charge density resulting from PAWGGA calculations. The energy results and the Bader charge analysis results obtained after the calculations are shown in Table 3.

Clearly the effect of inverse site occupation is reflected in the charges whereby In sites carry positive charges whereas $\mathrm{Au}$ is negatively charged. Comparing the $\left[\mathrm{In}_{6} \mathrm{Au}_{4}\right]^{\delta-}$ and $\left[\mathrm{Co}_{6} \mathrm{P}_{4}\right]^{\delta-}$ networks this switch in site occupancy is readily understandable on the basis of electronegativity arguments, $i$. $e$. the highly electronegative gold atoms substitute phosphorus. Consequently in these compounds the transition metal position adopts a positive charge whereas Au at $\mathrm{X} p$ element position is negatively charged. This is helped by the electronegativity magnitudes, larger for $\mathrm{Au}$ (2.54) versus In (1.78). The potassium compound is found more cohesive than the $\mathrm{Rb}$ one. This can be related to the volume differences $\mathrm{V}\left(\mathrm{KIn}_{6} \mathrm{Au}_{4}\right)=249.7 \AA^{3}$ versus $\mathrm{V}\left(\mathrm{RbIn}_{6} \mathrm{Au}_{4}\right)=253.5 \AA^{3}$. Although both $\mathrm{K}$ and $\mathrm{Rb}$ possess the same Pauling electronegativity of $\chi=0.82$, there is a larger charge transfer from potassium to the $\left[\mathrm{In}_{6} \mathrm{Au}_{4}\right]$ polyanionic substructure.

Fig. 5 shows the PDOS (top) and the COOP - bottom- for $\mathrm{KIn}_{6} \mathrm{Au}_{4}$. Due to the large filling of Au $5 d$ up to $\sim 10$ electrons, these $d$ states are found within the VB. This is also observed for the indium filled $d$ states found at $-15 \mathrm{eV}$ below $\mathrm{E}_{\mathrm{F}}$. The result is an itinerant electron system with EF crossing $s, p$ like states. Bonding is then expected to be mainly in the energy region around $\mathrm{Au} d$ states. This is illustrated in the lower panel showing over a narrower energy window for the sake of clarity the COOP for one atom of each kind to enable comparisons. The major bonding is for Au-In (as for Co-P in Fig. 4) at $-6 \mathrm{eV}$ as well as below $\mathrm{E}_{\mathrm{F}}$ all with mainly bonding character; antibonding COOP being mainly above $\mathrm{EF}_{\mathrm{F}}$, whereas the other interactions, $\mathrm{K}-\mathrm{In}$ and $\mathrm{K}-\mathrm{Au}$ are of vanishingly small magnitudes. These features resemble those found in the $\mathrm{MgCo}_{6} \mathrm{P}_{4}$ so that bonding is similar in both in spite of the inverse occupations.

\section{The superstructure of $\mathrm{ScRh}_{6} \mathrm{P}_{4}$}

$\mathrm{ScRh}_{6} \mathrm{P}_{4}[30]$ is a distorted variant of $\mathrm{LiCo}_{6} \mathrm{P}_{4}$. Two possible origins might be put forward to explain this feature:

- a geometrical consequence (puckering) due to the small scandium atoms 
- or an electronic structure reason.

The full geometry relaxation calculations show that the ground state is indeed the $P 3$ superstructure versus the $\mathrm{LiCo}_{6} \mathrm{P}_{4}$ type subcell with $\Delta \mathrm{E}=-0.045 \mathrm{eV} /$ cell, i.e. -0.004 eV/at. With this small energy magnitude and the close trends of Bader charges in both forms: $\sim \mathrm{Sc}^{+1.57}, \sim \mathrm{Rh} 1^{+0.04} \sim \mathrm{Rh}^{-0.20}$ and $\sim \mathrm{P}^{-0.27}$, the stabilization is more assignable to the puckering induced by the structural change due to size effects. Such geometrical factors have been observed for the superstructure formation of many intermetallic scandium compounds [32].

The large flexibility within the polyanionic networks of the $\mathrm{LiCo}_{6} \mathrm{P}_{4}$ type compounds readily reminds the large family of half-antiperovskites like $\operatorname{In} \operatorname{Sn}\left[\mathrm{Co}_{3} \mathrm{~S}_{2}\right]$ or $\mathrm{A}_{2}\left[\mathrm{Rh}_{3} \mathrm{~S}_{2}\right]$ (A = In, Sn, Pb, Tl) [33-35] which show similar electronic flexibility, although the sulphide substructure differs from the pnictides and tetrelides reported herein.

\subsection{Magnetic representatives based on Ce and $U$}

In the context of the peculiar crystal chemical characteristics of the A atom weakly bonded within the $\left[\mathrm{T}_{6} \mathrm{X}_{4}\right]$ building blocks, it becomes relevant to examine the effects on the magnetism at the levels of the $\mathrm{T}$ as well as the $\mathrm{A}$ atoms with $\mathrm{A}=\mathrm{Ce}, \mathrm{U}$.

\section{$\mathrm{CeRh}_{6} \mathrm{Si}_{4}$ and $\mathrm{CeRh}_{6} \mathrm{Ge}_{4}$}

As shown in Table 4 the calculated charge carried by Ce in both compounds does not give a hint on the valence state of Ce i.e. trivalent or intermediate valent [36]. Within the $\left[\mathrm{Rh}_{6} \mathrm{X}_{4}\right]$ networks $\mathrm{Rh}$ is negatively charged whereas the $\mathrm{X}$ atoms ( $\mathrm{Si}$ and $\mathrm{Ge}$ ) are positively charged. This follows from the larger Pauling electronegativity $\chi$ of $\mathrm{Rh}$ (2.28) versus $\mathrm{Si}$ (1.9) and $\mathrm{Ge}$ (2.01). Using the experimental structure data NSP calculations were carried out with the all electron scalar relativistic ASW method. The site projected DOS (PDOS) plots are shown in Fig. 5. The two panels show similar features pertaining to the presence of $\mathrm{Rh} 4 d$ states centered around $-3 \mathrm{eV}$ below the Fermi level within the VB, and $\mathrm{Si}$, Ge $p$ like states in the energy range $-6.5 /-4 \mathrm{eV}$ mixing with the Rh states. $\mathrm{Si}, \mathrm{Ge} s$ slike states are found at the lowest energy part of the VB. Differences appear at $\mathrm{E}_{\mathrm{F}}$ where $\mathrm{Ce} 4 f$ states are found crossed by $\mathrm{E}_{\mathrm{F}}$ at a finite DOS magnitude of $\sim 6 \mathrm{eV}^{-1}$ in the Ge compound, while they are found well within the $\mathrm{CB}$ in 
$\mathrm{CeRh}_{6} \mathrm{Si}_{4}$. This signals a possible magnetic instability for $\mathrm{CeRh}_{6} \mathrm{Ge}_{4}$ in such a NSP configuration.

SP calculations were subsequently carried out for both compounds. As expected no magnetic solution was found for $\mathrm{CeRh}_{6} \mathrm{Si}_{4}$ whereas finite magnetization developed ferromagnetically in $\mathrm{CeRh}_{6} \mathrm{Ge}_{4}$ with small moments magnitudes (moments in Bohr magnetons: $\left.\mu_{\mathrm{B}}\right): \mathrm{M}(\mathrm{Ce})=0.05 ; \mathrm{M}(\mathrm{Rh} 1)=0.16 ; \mathrm{M}(\mathrm{Rh} 2)=0.19 ; \mathrm{M}(\mathrm{Ge}) \sim 0.006-0.008$; $\mathrm{M}($ Cell $)=1.13 \mu \mathrm{B}$. However, larger integration of the $\mathrm{BZ}$ led to vanishing values meaning that there is no stable magnetic solution. Although an interpretation of this peculiarity will be provided upon discussing the results for the uranium compound, we develop further on this using complementary GGA+U calculations following the scheme of Dudarev et al. [37] were carried out to test the effect of increasing the correlations of the DFT exchange-correlation functional, GGA. $U$ stands for the Coulomb on-site repulsive parameter added to enhance correlation. The plain GGA scalar relativistic converged calculations are then used with $U=4 \mathrm{eV}$ acting on $4 f$ states. In both $\mathrm{CeRh}_{6} \mathrm{Si}_{4}$ and $\mathrm{CeRh}_{6} \mathrm{Ge}_{4}$, at self consistent convergence and high integration of the BZ, there is no onset of magnetic moment on any constituent, especially Ce. Note that the paramagnetic measured moment of $\mathrm{Ce}^{3+}$ is not in contradiction with our findings which only translate the solution of the absence of long range magnetic order. In other words a paramagnetic configuration is not possibly reproduced with SP calculations if no large supercells with random spin orientations are accounted for.

Lastly we mention that the synthesis of larger $\mathrm{CeRh}_{6} \mathrm{Ge}_{4}$ quantities for neutron diffractions studies is in progress.

\section{$\mathrm{UCr}_{6} \mathrm{P}_{4}$}

NSP calculation results are given for the PDOS at Fig. 6 (top). The uranium $5 f$ states are centered well above the Fermi level which crosses $\mathrm{Cr} 3 d$ states at a finite PDOS magnitude close to $\sim 7 \mathrm{eV}^{-1}$. Then any magnetic instability should arise from the spin polarization of the transition metal $(\mathrm{Cr})$ and not from uranium. Subsequent spinpolarized calculations for $\mathrm{UCr}_{6} \mathrm{P}_{4}$ led to finite moments (in $\mu_{\mathrm{B}}$ ):

$\mathrm{M}(\mathrm{U})=-0.52 ; \mathrm{M}(\mathrm{Cr} 2)=0.94 ; \mathrm{M}(\mathrm{Cr} 1)=1.07 ; \mathrm{M}(\mathrm{P}) \sim 0.006-0.008 ; \mathrm{M}(\mathrm{Cell})=5.54$ 
and a resulting ferrimagnetic like ground state. As a matter of fact the moment on uranium is carried by the itinerant $d$ and $f$ states which mix with those of $\mathrm{Cr} d$. The (genuine) polarization of the latter induces the moment carried by uranium. This is further reflected by the SP PDOS shown in the lower panel of Fig. 5 for majority ( $\uparrow$ ) and minority $(\downarrow)$ spin populations. There is a downwards energy shift of majority $\mathrm{Cr} 3 d$ states, opposed to upward minority whence the moment $m(\mathrm{Cr})=\mathrm{n}(\uparrow)-\mathrm{n}(\downarrow)$ whence the appellation of majority versus minority populations. The opposite is observed for uranium whence its negative moment. The difference between the Ce and $\mathrm{U}$ compounds is in the nature of the transition metal which shows a trend to developing a magnetic moment when it is of the first period $(\mathrm{Cr} 3 d)$ and less tendency to polarize when it belongs the $2^{\text {nd }}$ period as for $\mathrm{Rh}$.

Also further GGA $+U$ calculations led to the same ferrimagnetic solution with an enhancement of the magnetic moments (in $\left.\mu_{\mathrm{B}}\right)$ : $\mathrm{M}(\mathrm{U})=-1.87 ; \mathrm{M}(\mathrm{Cr} 2)=0.62 ; \mathrm{M}(\mathrm{Cr} 1)$ $=1.15 ; \mathrm{M}(\mathrm{P}) \sim 0.06-0.08 ; \mathrm{M}(\mathrm{Ce} l \mathrm{l})=3.58$. Neutron diffraction experiments would be needed to clearly establish the magnetic structure.

Summing up, the family of $\mathrm{LiCo}_{6} \mathrm{P}_{4}$ type compounds exhibits interesting coloring on all positions. Leading to several tetrelides and pnictides and also some antitype compounds like $\mathrm{KIn}_{6} \mathrm{Au}_{4}$ and $\mathrm{RbIn}_{6} \mathrm{Au}_{4}$ where the transition metal and $p$ element sites interchange as a consequence of the electronegative range. Chemical bonding analyses nicely underlines the variations within the different polyanionic networks. The $\mathrm{LiCo}_{6} \mathrm{P}_{4}$ family covers a variety of non-magnetic members but also paramagnetic ones like $\mathrm{CeRh}_{6} \mathrm{Si}_{4}$ and $\mathrm{CeRh}_{6} \mathrm{Ge}_{4}$ and the calculations also point to chromium magnetism in $\mathrm{UCr}_{6} \mathrm{P}_{4}$.

\section{Acknowledgments}

This work was financially supported by the Deutsche Forschungsgemeinschaft. We acknowledge support from the Conseil Régional d'Aquitaine. Computational facilities were provided by MCIA-Université de Bordeaux clusters. 


\section{References}

[1] R. Buschmann, H.-U. Schuster, Z. Naturforsch. 1991, 46b, 699.

[2] A. Hellmann, A. Mewis, Z. Anorg. Allg. Chem. 2001, 627, 1357.

[3] A. Wurth, A. Mewis, Z. Anorg. Allg. Chem. 1999, 625, 449.

[4] W. Jeitschko, R. Brink, Z. Naturforsch. 1992, 47b, 192.

[5] A. Lipatov, A. Gribanov, A. Grytsiv, S. Safronov, P. Rogl, J. Rousnyak, Y. Seropegin, G. Giester, J. Solid State Chem. 2010, 183, 829.

[6] D. Voßwinkel, O. Niehaus, U. Ch. Rodewald, R. Pöttgen, Z. Naturforsch. 2012, $67 b, 1241$.

[7] B. Li, J. D. Corbett, Inorg. Chem. 2007, 46, 6022.

[8] D. Voßwinkel, O. Niehaus, R. Pöttgen, Z. Anorg. Allg. Chem. 2013, 639, 2623.

[9] S. F. Matar, A. Al-Alam, N. Ouaini, R. Pöttgen, J. Solid State Chem. 2013, 202, 227.

[10] R. Pöttgen, T. Dinges, H. Eckert, P. Sreeraj, H.-D. Wiemhöfer, Z. Phys. Chem. 2010, 224, 1475.

[11] A. Kuhn, P. Sreeraj, R. Pöttgen, H.-D. Wiemhöfer, M. Wilkening, P. Heitjans, J. Am. Chem. Soc. 2011, 133, 11018.

[12] T. Langer, S. Dupke, H. Eckert, S. F. Matar, M. Winter, R. Pöttgen, Solid State Sci. 2012, 14, 367.

[13] S. F. Matar, R. Pöttgen, Solid State Sci. 2012, 14, 1471.

[14] P. Hohenberg, W. Kohn, Phys. Rev. 1964, 136, B864.

[15] W. Kohn, L. J. Sham, Phys. Rev. 1965, 140, A1133.

[16] G. Kresse, J. Furthmüller, Phys. Rev. B 1996, 54, 11169.

[17] G. Kresse, J. Joubert, Phys. Rev. B 1999, 59, 1758.

[18] J. P. Perdew, K. Burke, M. Ernzerhof, Phys. Rev. Lett. 1996, 77, 3865.

[19] D. M. Ceperley, B. J. Alder, Phys. Rev. Lett. 1980, 45, 566.

[20] W. H. Press, B. P. Flannery, S. A. Teukolsky, W. T. Vetterling, Numerical Recipes, Cambridge University Press, New York, 1986.

[21] P. E. Blöchl, Phys. Rev. B 1994, 50, 17953.

[22] M. Methfessel, A.T. Paxton, Phys. Rev. B 1989, 40, 3616.

[23] A. R. Williams, J. Kübler, C. D. Gelatt Jr., Phys. Rev. B 1979, 19, 6094.

[24] V. Eyert, The Augmented Spherical Wave Method - A Comprehensive Treatment, Lecture Notes in Physics, Springer, Heidelberg, 2007.

[25] R. Hoffmann, Angew. Chem. Int. Ed. Engl. 1987, 26, 846.

[26] J. Emsley, The Elements, Oxford University Press, Oxford, 1999.

[27] J. Donohue, The Structures of the Elements, Wiley, New York, 1974. 
[28] R.-D. Hoffmann, R. Pöttgen, C. Rosenhahn, B. D. Mosel, B. Künnen, G. Kotzyba, J. Solid State Chem. 1999, 145, 283.

[29] R.-D. Hoffmann, R. Pöttgen, Z. Anorg. Allg. Chem. 1999, 625, 994.

[30] U. Pfannenschmidt, U. C. Rodewald, R. Pöttgen, Monatsh. Chem. 2011, 142, 219.

[31] R. F. W. Bader, Chem. Rev. 1991, 91, 893.

[32] H. Eckert, R. Pöttgen, Z. Anorg. Allg. Chem. 2010, 636, 2232.

[33] R. Weihrich, S. F. Matar, V. Eyert, F. Rau, M. Zabel, M. Andratschke, I. Anusca, Th. Bernert, Prog. Solid State Chem. 2007, 35, 309.

[34] A. Anusca, Ph. P. Schmid, J. Rothballer, F. Pielnhofer, R. Weihrich, Z. Anorg. Allg. Chem. 2009, 635, 2410.

[35] F. Rothballer, F. Bachhuber, F. Pielnhofer, F. M. Schappacher, R. Pöttgen, R. Weihrich, Eur. J. Inorg. Chem. 2013, 248.

[36] S. F. Matar, Prog. Solid State Chem. 2013, 41, 55.

[37] S. L. Dudarev, G. A. Botton, S. Y. Savrasov, C. J. Humphreys, A. P. Sutton, Phys. Rev. B 57 (1998) 1505.

Table 1. Site occupancies for intermetallic compounds with hexagonal $\mathrm{LiCo}_{6} \mathrm{P}_{4}$ type structure.

\begin{tabular}{lcccccc}
\hline Compound & $1 a$ & $1 c$ & $3 j$ & $3 k$ & $3 k$ & Reference \\
\hline $\mathrm{LiCo}_{6} \mathrm{P}_{4}$ & $\mathrm{Li}$ & $\mathrm{P} 1$ & $\mathrm{Co} 1$ & $\mathrm{Co} 2$ & $\mathrm{P} 2$ & {$[1]$} \\
$\mathrm{MgCo}_{6} \mathrm{P}_{4}$ & $\mathrm{Mg}$ & $\mathrm{P} 1$ & $\mathrm{Co} 1$ & $\mathrm{Co} 2$ & $\mathrm{P} 2$ & {$[2]$} \\
$\mathrm{MgRh}_{6} \mathrm{P}_{4}$ & $\mathrm{Mg}$ & $\mathrm{P} 1$ & $\mathrm{Rh} 2$ & $\mathrm{Rh} 1$ & $\mathrm{P} 2$ & {$[3]$} \\
$\mathrm{UCr}_{6} \mathrm{P}_{4}$ & $\mathrm{U}$ & $\mathrm{P} 1$ & $\mathrm{Cr} 2$ & $\mathrm{Cr} 1$ & $\mathrm{P} 2$ & {$[4]$} \\
$\mathrm{MgRh}_{6} \mathrm{As}_{4}$ & $\mathrm{Mg}$ & $\mathrm{As} 1$ & $\mathrm{Rh} 2$ & $\mathrm{Rh} 1$ & $\mathrm{As} 2$ & {$[3]$} \\
$\mathrm{CaRh}_{6} \mathrm{As}_{4}$ & $\mathrm{Ca}$ & $\mathrm{As} 1$ & $\mathrm{Rh} 2$ & $\mathrm{Rh} 1$ & $\mathrm{As} 2$ & {$[3]$} \\
$\mathrm{SrRh}_{6} \mathrm{As}_{4}$ & $\mathrm{Sr}$ & $\mathrm{As} 1$ & $\mathrm{Rh} 2$ & $\mathrm{Rh} 1$ & $\mathrm{As} 2$ & {$[3]$} \\
$\mathrm{YbRh}_{6} \mathrm{As}_{4}$ & $\mathrm{Yb}$ & $\mathrm{As} 1$ & $\mathrm{Rh} 2$ & $\mathrm{Rh} 1$ & $\mathrm{As} 2$ & {$[3]$} \\
$\mathrm{CeRh}_{6} \mathrm{Si}_{4}$ & $\mathrm{Ce}$ & $\mathrm{Si} 1$ & $\mathrm{Rh} 2$ & $\mathrm{Rh} 1$ & $\mathrm{Si} 2$ & {$[5]$} \\
$\mathrm{CeRh}_{6} \mathrm{Ge}_{4}$ & $\mathrm{Ce}$ & $\mathrm{Ge} 1$ & $\mathrm{Rh} 2$ & $\mathrm{Rh} 1$ & $\mathrm{G} 2$ & {$[6]$} \\
$\mathrm{KIn}_{6} \mathrm{Au}_{4}$ & $\mathrm{~K}$ & $\mathrm{Au} 1$ & $\mathrm{In} 2$ & $\mathrm{In} 1$ & $\mathrm{Au} 2$ & {$[7]$} \\
$\mathrm{RbIn}_{6} \mathrm{Au}_{4}$ & $\mathrm{Rb}$ & $\mathrm{Au} 1$ & $\mathrm{In} 2$ & $\mathrm{In} 1$ & $\mathrm{Au} 2$ & {$[7]$} \\
\hline
\end{tabular}


Table 2. Experimental [2] and (calculated) crystal data for $\mathrm{MgCo}_{6} \mathrm{P}_{4}: a=6.609$ (6.56), $c=3.380$ (3.36) $\AA$.

\begin{tabular}{lcccc}
\hline Atom & site & $x$ & $y$ & $z$ \\
\hline $\mathrm{Mg}$ & $1 a$ & 0 & 0 & 0 \\
$\mathrm{Co} 1$ & $3 k$ & $0.5355(0.535)$ & $2 x$ & $1 / 2$ \\
$\mathrm{Co} 2$ & $3 j$ & $0.1996(0.199)$ & $2 x$ & 0 \\
$\mathrm{P} 1$ & $3 k$ & $0.8151(0.813)$ & $2 x$ & $1 / 2$ \\
$\mathrm{P} 2$ & $1 c$ & $1 / 3$ & $2 / 3$ & 0 \\
\hline
\end{tabular}

Table 3. Average Bader charges and total energy per formula unit and cohesive energies per atom for $\mathrm{KIn}_{6} \mathrm{Au}_{4}$ and $\mathrm{RbIn}_{6} \mathrm{Au}_{4}(\mathrm{~A}=\mathrm{K}, \mathrm{Rb})$.

\begin{tabular}{|l|l|l|l|l|l|}
\hline & $\mathrm{Q}_{\text {In }}$ & $\mathrm{Q}_{\mathrm{Au}}$ & $\mathrm{Q}_{\mathrm{A}}$ & $\mathrm{E}_{\text {tot. }}(\mathrm{eV})$ & $\Delta \mathrm{E}_{\text {at. }}(\mathrm{eV})$ \\
\hline $\mathrm{KIn}_{6} \mathrm{Au}_{4}$ & +0.50 & -0.93 & +0.72 & -31.876 & -0.308 \\
\hline $\mathrm{RbIn}_{6} \mathrm{Au}_{4}$ & +0.51 & -0.93 & +0.66 & -31.539 & -0.284 \\
\hline
\end{tabular}

Individual constituents: $\mathrm{E}(\mathrm{K}-\mathrm{bcc})=-1.01 \mathrm{eV} ; \mathrm{E}(\mathrm{Rb}-\mathrm{bcc})=-0.94 \mathrm{eV} ; \mathrm{E}(\mathrm{In}-$ simple tetragonal $)=-2.44 \mathrm{eV}$ and $\mathrm{E}(\mathrm{Au}-\mathrm{fcc})=-3.21 \mathrm{eV}$.

Table 4. Average Bader charges and total energy per formula unit and cohesive energies per atom for $\mathrm{CeRh}_{6} \mathrm{Si}_{4}$ and $\mathrm{CeRh}_{6} \mathrm{Ge}_{4}(\mathrm{X}=\mathrm{Si}, \mathrm{Ge})$.

\begin{tabular}{|l|l|l|l|l|l|}
\hline & QRh & Qx & Qce & $E_{\text {tot. }}(\mathrm{eV})$ & $\Delta \mathrm{E}_{\text {at. }}(\mathrm{eV})$ \\
\hline $\mathrm{CeRh}_{6} \mathrm{Si}_{4}$ & -0.60 & +0.54 & +1.44 & -82.12 & -1.014 \\
\hline $\mathrm{CeRh}_{6} \mathrm{Ge}_{4}$ & -0.58 & +0.51 & +1.42 & -75.84 & -0.777 \\
\hline
\end{tabular}

Individual constituents: $\mathrm{E}(\mathrm{Ce}-\mathrm{hex})=.-5.71 \mathrm{eV} ; \mathrm{E}(\mathrm{Rh}-\mathrm{fcc})=-7.27 \mathrm{eV}, \mathrm{E}(\mathrm{Si}-\mathrm{fcc}$ Blende $)=-5.41 \mathrm{eV}$ and $\mathrm{E}(\mathrm{Ge}-\mathrm{fcc}$ Blende $)=-4.49 \mathrm{eV}$. 


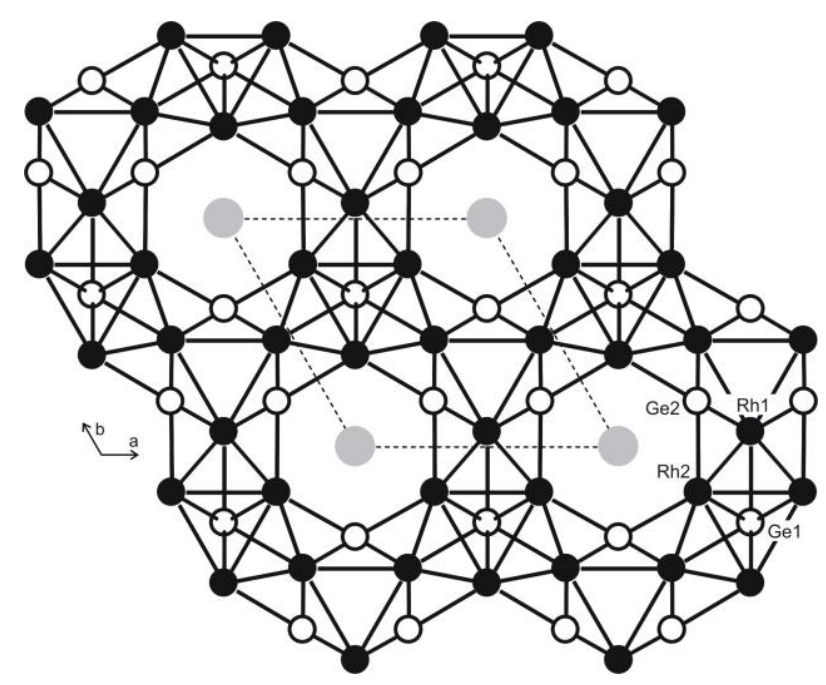

Fig. 1. View of the $\mathrm{CeRh}_{6} \mathrm{Ge}_{4}$ structure along the $c$ axis. Cerium, rhodium, and germanium atoms are drawn as medium grey, black filled and open circles, respectively. The three-dimensional [ $\left.\mathrm{Rh}_{6} \mathrm{Ge}_{4}\right]$ network with $\mathrm{Rh}-\mathrm{Rh}$ and $\mathrm{Rh}-\mathrm{Ge}$ contacts is emphasized. The crystallographically independent rhodium and germanium sites are marked at the lower right-hand part.

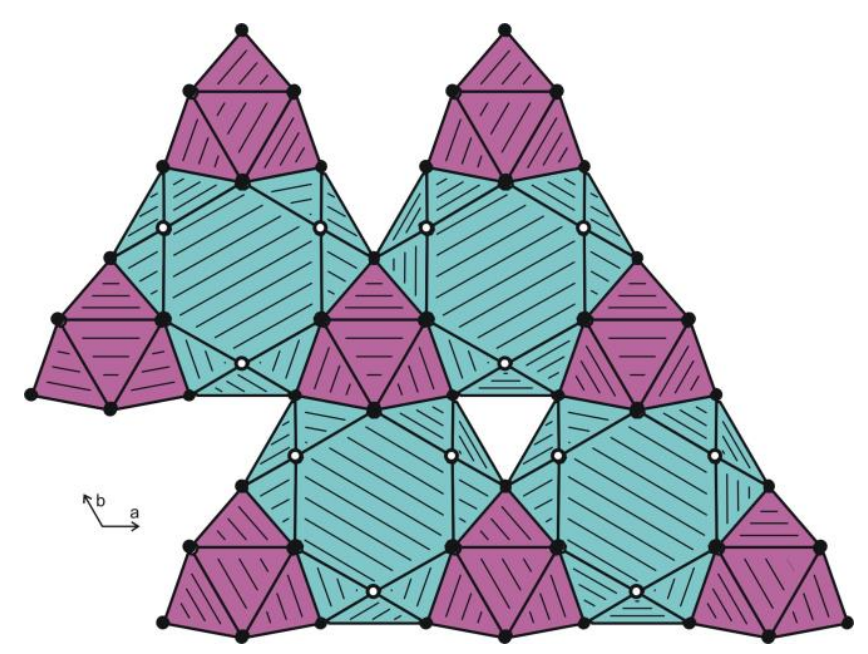

Fig. 2. (color online) The crystal structure of $\mathrm{CeRh}_{6} \mathrm{Ge}_{4}$. The $\mathrm{Ce}_{0} @ \mathrm{Ge}_{6} \mathrm{Rh}_{12}$ (blue color) and Ge1@Rh9 (red color) polyhedra are emphasized. The centres of the cerium polyhedra span the hexagonal unit cell. 


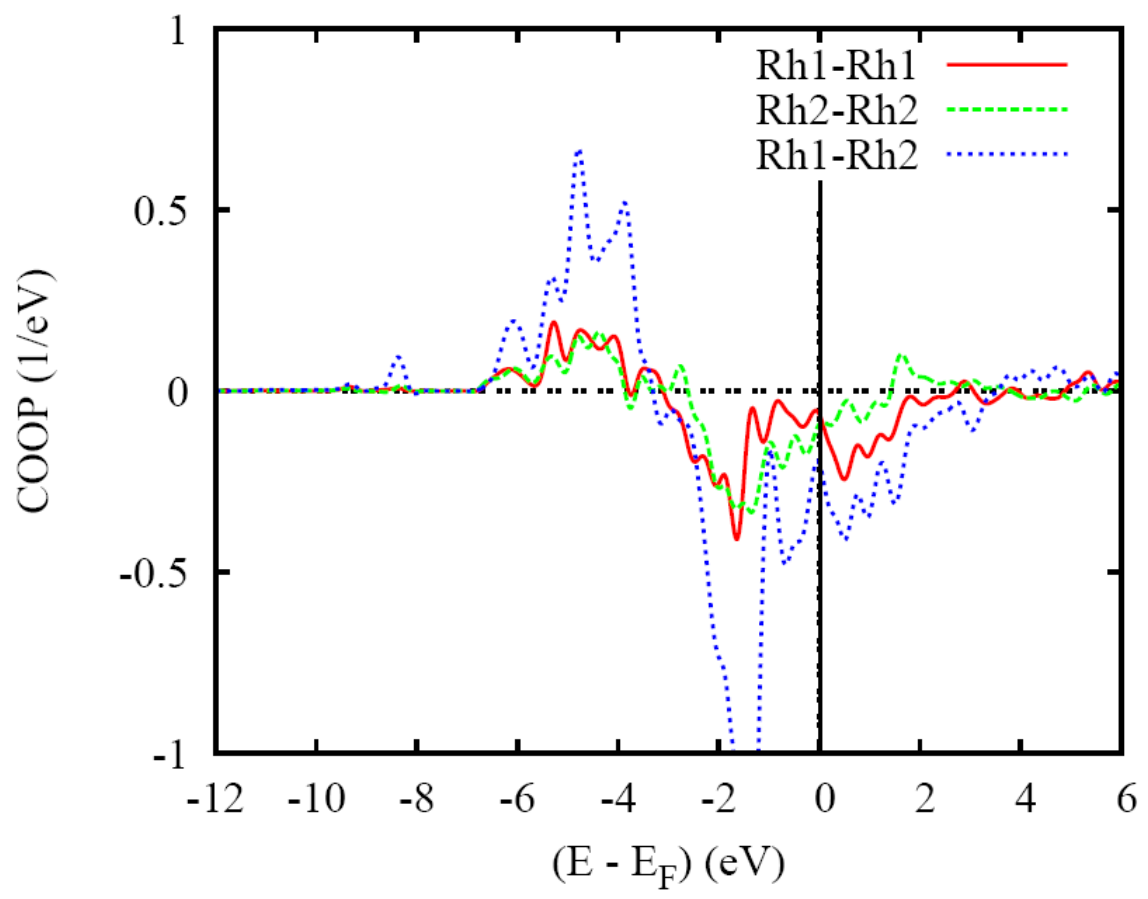

Fig. 3. (color online) The nature of the $\mathrm{Rh}-\mathrm{Rh}$ interactions in $\mathrm{CeRh}_{6} \mathrm{Ge}_{4}$ from the analysis of the overlap integrals $S_{i j}$ within the COOP scheme. Positive and negative COOP magnitudes are respectively bonding and antibonding. 

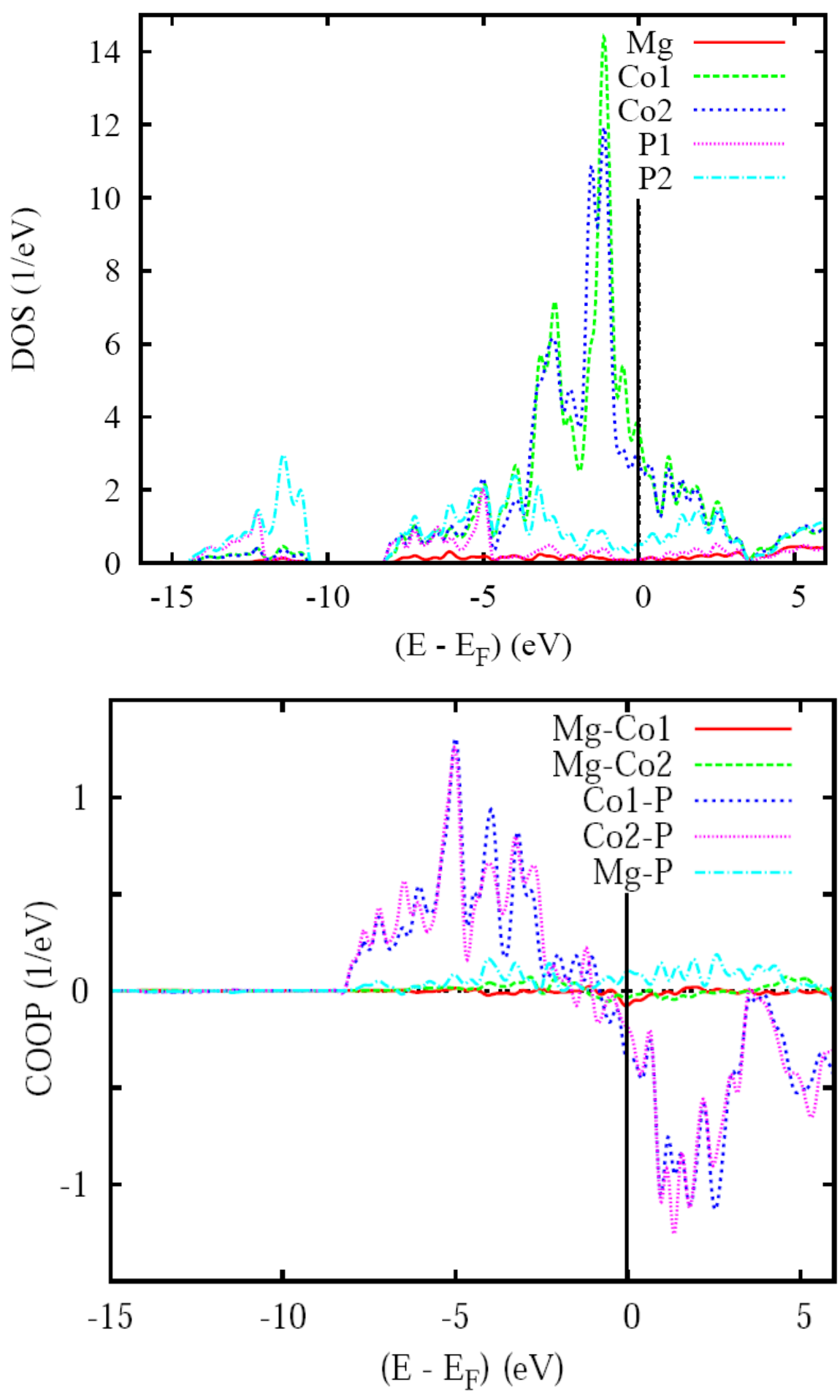

Fig. 4. (color online) $\mathrm{MgCo}_{6} \mathrm{P}_{4}$ site projected density of states (top) and chemical bonding (bottom). 

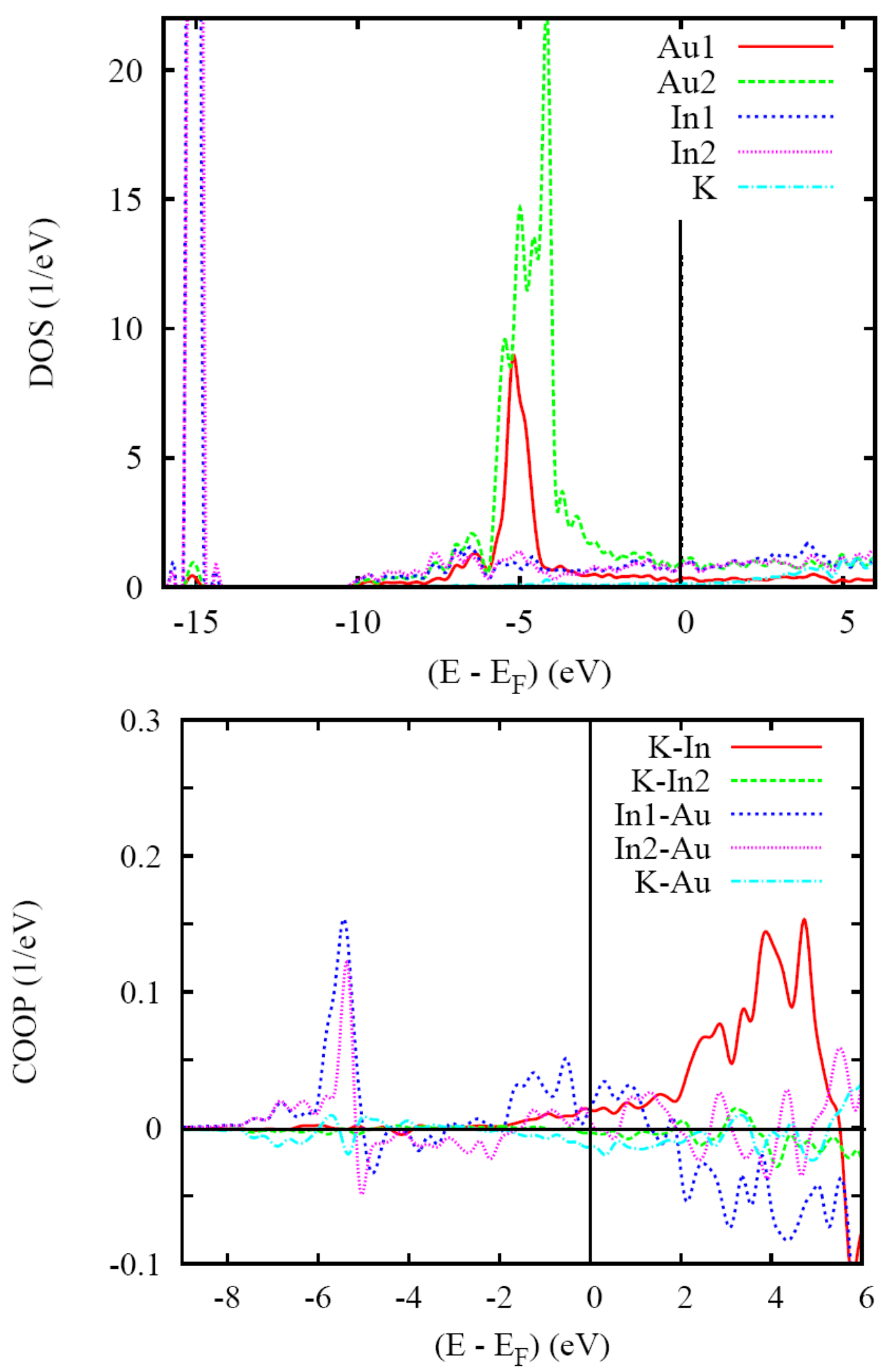

Fig. 5 (color online) $\mathrm{KIn}_{6} \mathrm{Au}_{4}$ site projected density of states (top) and chemical bonding (bottom). 

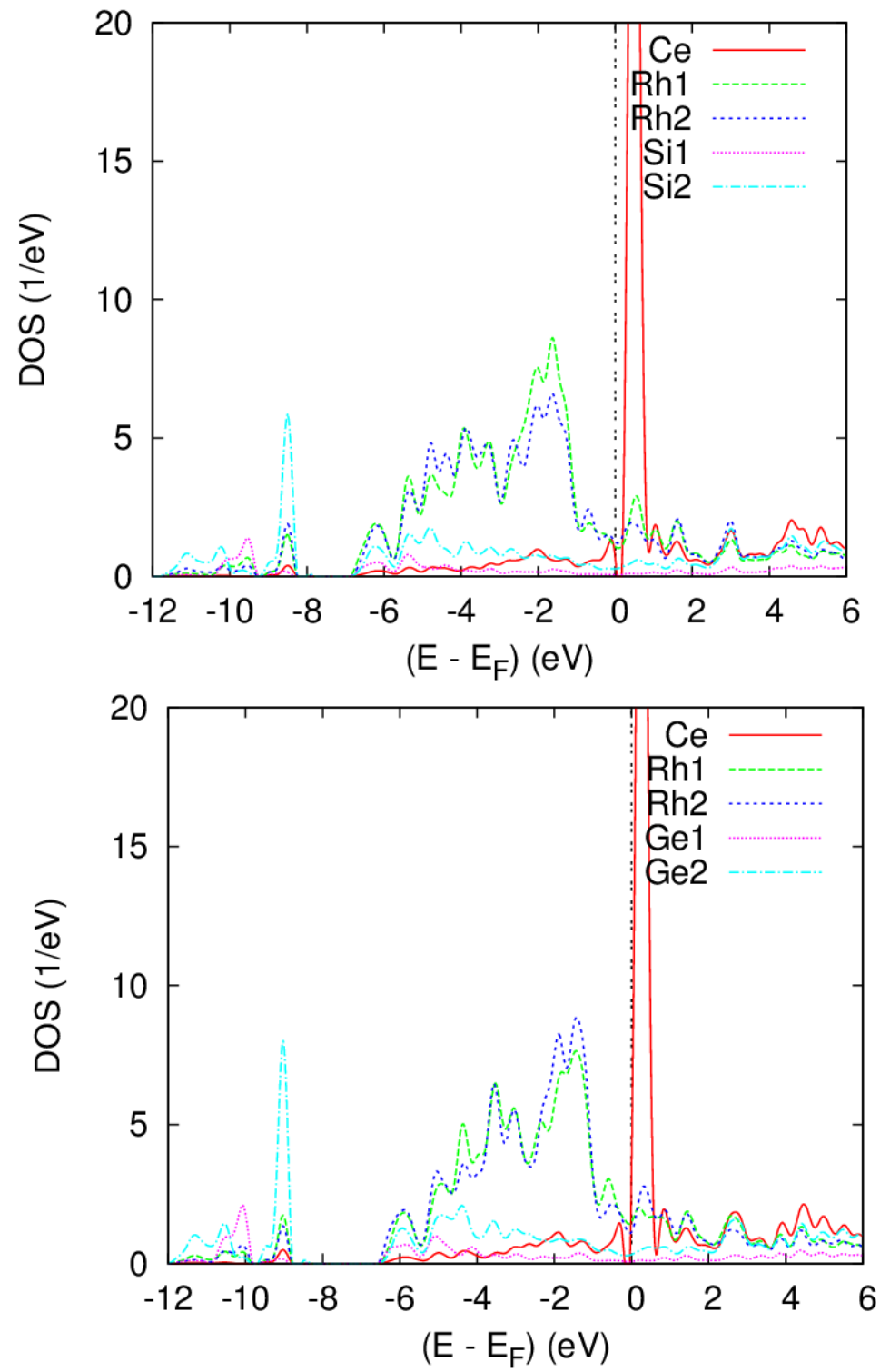

Fig. 6. (color online) $\mathrm{CeRh}_{6} \mathrm{X}_{4} \mathrm{NSP}$ PDOS for $\mathrm{X}=\mathrm{Si}$ (top) and for $\mathrm{X}=\mathrm{Ge}$ (bottom). 

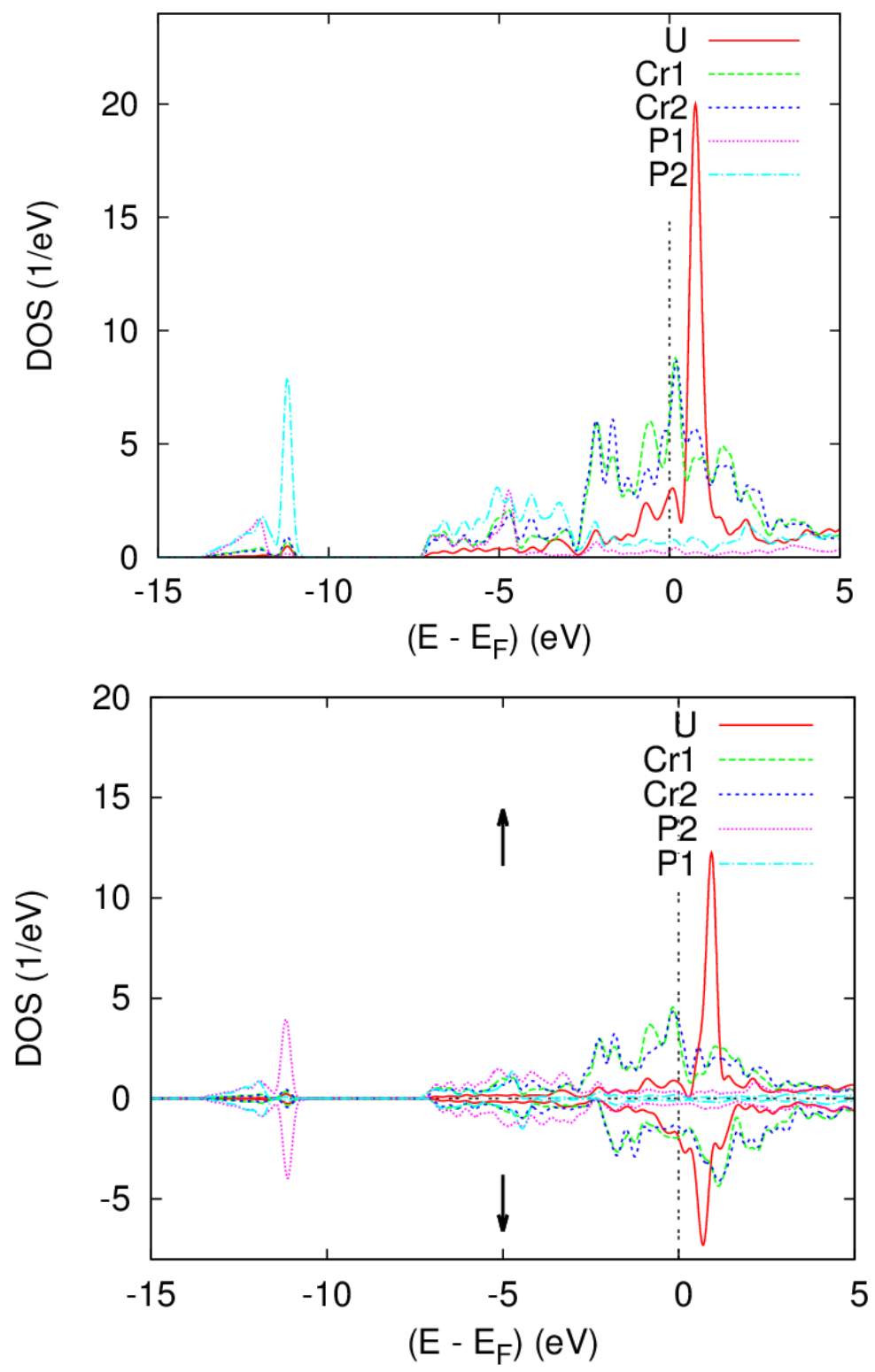

Fig. 7. (color online) $\mathrm{UCr}_{6} \mathrm{P}_{4}$ : NSP PDOS (top) and SP PDOS (bottom). 